\title{
La educación en tiempos de crisis. Diálogos en torno a lo humano
}

[Artículos de reflexión]

\author{
Reina Saldaña Duque* \\ Christian Andrés Hernández Rodríguez ${ }^{* *}$ \\ Stella Pino Salamanca ${ }^{* * *}$ \\ Luis Alberto Montenegro Mora ${ }^{* * * *}$
}

Recibido: 11 de noviembre de 2020

Aceptado: 11 de febrero de 2021

Citar como:

Saldaña, R., Hernández, C., Pino, S. y Montenegro, L. (2021). La educación en tiempos de crisis. Diálogos en torno a lo humano. Campos en Ciencias Sociales, 9(1). https://doi.org/10.15332/25006681.6922

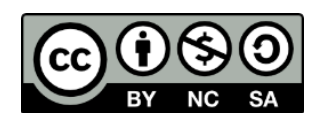

\section{Resumen}

Este texto es resultado de las reflexiones sobre el lugar de la educación en estos tiempos de pandemia desde el rol del estudiante. La conversación se sitúa en las simetrías y asimetrías educativas en estos momentos de tensiones, crisis y novedades sociales, educativas, económicas y políticas

\footnotetext{
* Magíster de la Universidad de San Buenaventura, Cali, Colombia. Correos electrónicos: queen4419@hotmail.com, rsaldana@usbcali.edu.co; ORCID: https://orcid.org/00000002-6224-4911

** Magíster de la Universidad del Valle, Cali, Colombia. Correos electrónicos: christianandreshernandez@gmail.com, cahernandez4@usbcali.edu.co; ORCID: https://orcid.org/0000-0001-8364-5178

*** Doctora de la Universidad de San Buenaventura, Cali, Colombia. Correos electrónicos: stellapinosalamanca@gmail.com, stellapino@unicauca.edu.co; ORCID: https://orcid.org/0000-0002-0386-3990

${ }^{* * * *}$ Magíster de la Universidad de Nariño, Pasto, Colombia. Correos electrónicos: lamontenegrom@gmail.com, lamontenegrom@udenar.edu.co; ORCID:

https://orcid.org/0000-0002-4945-3751
} 
por las que transita el ser humano. Se observa entonces que la educación ha cambiado y seguirá cambiando desde el espacio físico, las relaciones, los métodos de enseñanza, los currículos y las comunicaciones, lo que nos invita a centrar la mirada en la fragilidad de lo humano. Así las cosas, se propone abordar cuatro momentos; el primero contempla la relación entre sociedad y escuela; el segundo pregunta por el lugar de lo humano en la educación; el tercero invita a la reflexión en torno a la educación en tiempos de pandemia, como un asunto para seguir repensando, y el cuarto aborda la siguiente pregunta: ¿de qué escuela debemos empezar a hablar? Se reflexiona sobre saberes, prácticas y discursos que han venido concurriendo en el actual cambio de época y sobre las tensiones y dinámicas que afectan el acto educativo y, con ello, la experiencia humana.

Palabras claves: humanidad, escuela, educación, diálogo, pedagogía.

\section{Education in Times of Crisis. Dialogues Around the Human}

\section{Abstract}

This article is the result of reflections on the place of education in times of pandemic from the role of the student. The conversation is situated in educational symmetries and asymmetries in these times of tensions, crises, and social, educational, economic, and political changes. It is then observed that education has changed and will continue to change from the physical space, relationships, teaching methods, curricula, and communications, which invites us to focus on the fragility of the human. Thus, we propose to address four moments: the first one considers the relationship between society and school; the second inquires about the place of the human in education; the third invites us to reflect on education in times of pandemic, as a topic to reconsider; and the fourth addresses a questioning on the type of school we should start talking about. We then reflect on knowledge, practices, and discourses that have been concurring in the current change of era, and on the tensions and 
dynamics that affect the educational act and, with it, the human experience.

Keywords: humanity, school, education, dialogue, pedagogy.

\section{Introducción}

Hacia el 23 de marzo del presente año (2021) se hacía público en el país el Decreto 457 con cual se reglamentaba el "Aislamiento preventivo obligatorio", para todos los habitantes de la República de Colombia a partir del 25 de marzo. Lo que inicialmente se había proyectado para 19 días se fue ampliando por momentos en los que se incluían cada vez más especificaciones y excepciones. En este marco, las dinámicas sociales, culturales, económicas y políticas tuvieron que modificarse a raíz de lo que sale a relucir con el covid-19.

Por supuesto, uno de los campos que mayor afectación tuvo y que, a su vez, generó grandes impactos en los distintos ámbitos de la vida en sociedad fue el educativo. Con el cierre de colegios, fundaciones, institutos y universidades la escuela no fue la misma; las aulas se trasladaron a las salas, habitaciones y escaleras de las casas de estudiantes y profesores, los padres tuvieron que afrontar desde adentro todo aquello que el espacio físico de las instituciones educativas solía suplir. Por supuesto, en un país con el grado de inequidad en el que cada persona se encuentra, los sujetos no sufrieron los mismos grados de afectación. Mientras algunas familias solo tenían que lidiar con el sentimiento de incertidumbre que genera cualquier tipo de confinamiento que no es voluntario, muchas otras se debatían en si arriesgar su vida saliendo a la calle a conseguir el sustento diario o quedarse en casa viendo como todos sus seres queridos, generalmente en condiciones de hacinamiento, intentaban hacer alcanzar lo poco que se puede guardar en los inexistentes refrigeradores que deben surtirse a diario con el resultado de lo que el día les permita conseguir. 
Ante este panorama, por cierto, complejo y en algunos casos todavía irresoluto, esta reflexión se ubica desde el lugar del estudiante, de unos estudiantes que se sitúan en el suroccidente de Colombia entre los departamentos de Valle del Cauca, Cauca y Nariño; particularmente, espacios en los que los índices de marginación antes y después de la pandemia siguen siendo alarmantes. La conversación se sitúa en las simetrías y asimetrías educativas en estos momentos de tensiones, crisis y novedades sociales, educativas, económicas entre otras, por las que transita el ser humano. Se observa entonces que la educación ha cambiado y seguirá cambiando desde el espacio físico, las relaciones, los métodos, los currículos p las comunicaciones, lo que invita a centrar la mirada en la fragilidad: lo contingente de lo humano.

Así las cosas, el texto se estructura en cuatro apartados. El primero, "Comunidad, sociedad y escuela. Diálogo en torno a la educación", contempla los abordajes desde los cuales vale la pena pensarse en lo comunal en contextos escolares. El segundo, "El lugar de lo humano en la educación", pregunta por el momento de lo humano en contextos de pandemia. El tercero, "Educación en tiempos de pandemia, un asunto para seguir repensando", reflexiona cobre el estado actual de los seres humanos; y el cuarto, "Educación en tiempos de pandemia: ¿de qué escuela debemos empezar a hablar?”, discurre alrededor de algunos saberes, prácticas y discursos que han venido concurriendo en el actual cambio de época, las tensiones y dinámicas que afectan el acto educativo y con ello la experiencia humana. 


\section{Comunidad, sociedad y escuela. Diálogo en torno a la educación}

Para iniciar, vale la pena situar desde dónde se habla de comunidad, de

sociedad y de escuela. Lo primero es ubicarse en lo dispuesto por Ferdinand Tönnies en 1947, citado por Álvaro (2010):

Comunidad es lo antiguo y sociedad lo nuevo, como cosa y nombre [...] comunidad es la vida en común duradera y auténtica; sociedad es sólo una vida en común pasajera y aparente. Con ello coincide el que la comunidad misma deba ser entendida a modo de organismo vivo, y la sociedad como agregado y artefacto mecánico. (p. 16)

Así las cosas, en la comunidad se despliega una vida auténtica y real, experiencias con el otro, con los otros. Es en la comunidad donde el ser humano se forma, donde se dan las relaciones, las colectividades, los acuerdos, los desaciertos y tensiones que posibilitan al hombre actuar, decir, hacer y crear: "[...] la comunidad a la sociedad describe el 'movimiento total' que va de lo simple a lo complejo, de lo duradero y auténtico a lo pasajero y aparente, de lo orgánico-natural a lo suplementario y artefactual” (p. 16).

Se mira entonces una vida comunitaria donde los seres humanos van configurando las subjetividades, los saberes y las acciones que enlazan sus modos de actuar y que se llevan a la escuela. Una escuela que olvida los contextos, los ritmos de la vida misma y la naturaleza de las comunidades y que cada vez se distancia más de estas. La comunidad hoy evidencia que ha estado presente en el núcleo familiar y que desde allí se afinca para poder recrearse y pronunciarse, sin embargo, el actual cambio de época vuelve, retorna a las entrañas filiales donde el hombre olvida su núcleo primario y natural de expresión. Es aquí donde la escuela hoy en medio de esta crisis de humanidad, crisis educativa, requiere repensarse.

Respecto a esto, es importante indicar que la escuela no puede darle la espalda a lo que acontece, por eso se ve retada a nuevas transformaciones, porque, 
así como cambian los sujetos y con ello la mirada de la comunidad en la sociedad, cambian las condiciones en las que esta ha estado situada. Hay una necesidad de cambio en la escuela, entendiendo que esta ha sido una escuela que se ha pensado desde adentro, sin poner o centrar la atención en el afuera para establecer diálogos interculturales entre las dinámicas monoculturales y las perspectivas y tradiciones propias.

Hoy, se han transformado los sujetos, los entornos y las maneras de enseñar y aprender; los métodos, técnicas y estrategias de estudio han llevado a dar giros que muy seguramente ya se habían pensado desde el mismo desarrollo de la ciencia y la tecnología en otrora, lo cual ha permeado desde todas las aristas el mundo educativo. Una educación que pasa de presencialidades a momentos simulados virtuales; de contactos físicos, palabras y alientos frente al tono del otro, que desde la mirada ya dice y provoca, a las barreras mecánicas situadas y estáticas que el llamado docente y el llamado estudiante deben tratar de fisurar. Entonces, ¿dónde está lo humano en estos tiempos de mediaciones tecnológicas?, ¿cuál es el llamado a la escuela?, ¿de qué educación se habla hoy?, ¿a qué llamamos escuela?, ¿cuál es la función de la escuela?

Es importante indicar que la familia es y ha sido fundamental en la educación de los seres humanos, que los padres son los aliados, compañeros y anclas en este caminar de la vida. Sin embargo, la escuela es otra cosa, la escuela hoy se enfrenta a una concepción de sí misma extendida por los apoyos tecnológicos, que, si bien se venían dando de manera somera, hoy se hacen homogéneos por la urgencia de estar confinados y encerrados y preservar la vida. Pero, ¿cómo se enseña?, ¿cómo se aprende?, es desde este lugar done, como estudiantes y docentes, se miran ciertos desafíos en el campo de la relación comunidad-escuela-sociedad. Desafíos que pasan por un virus que en este momento es adverso a la educación presencial, como se venía desarrollando; por el refinar la mirada reconociendo que el 
aprendizaje del otro es diferente al propio; por pensar cómo desafiar estas tecnologías que no son nuevas ni antiguas, son soportes tecnológicos en esta gran emergencia, o por reconocer las maneras de estar en este tiempo. Es importante lograr un estar en mayúscula desde el lugar que a cada uno lo convoque, que reconozca que el actual mundo tecnológico está dado y que de cada uno depende crear dioses o matar dioses; el reto educativo también pasa por tener presente de qué libertad se puede hablar hoy, ¿de una libertad de puertas para dentro?, ¿una simulada, donde las tecnologías son los nuevos panópticos?; así mismo, el desafío está en comprender que esta "nueva" sociedad con sus tecnologías ha descentralizado la escuela y seguramente ya no será la figura que se venía abordando, posiblemente las diferentes instituciones le vayan dando otros lugares, como hoy a cada uno le ha tocado ver, acompañar y sentir.

Finalmente, vale la pena pensar de qué comunidad humana se habla ahora; mirar los ritmos del tiempo, del aburrimiento, de la soledad y de la individualidad, que tocan a cada ser humano sin importar el lugar en el que se encuentre, y revisar las asimetrías en la enseñanza, asimetrías en los insumos, en las herramientas y, hasta, en las mismas comprensiones e interpretaciones de los encuentros o desencuentros educativos; de ahí que se haga necesaria una enseñanza y un aprendizaje desde la crítica. Crítica a lo que se vive en el mundo actual, a las grandes hipótesis del covid-19, a las grandes medidas de gobierno para enfrentar el virus, a la crisis humana que padece el mundo entero y a la individualidad que toca las puertas de la sociedad. Y sobre todo es fundamental seguirse pensando, seguir reflexionando en Cómo enseñar para ensanchar la humanidad. De tal manera que las acciones y las prácticas educativas sean verdaderas experiencias de mundo. 


\section{El lugar de lo humano en la educación}

Para hablar de lo humano en la educación se proponen tres reflexiones a partir de lo que se ha denominado "el lugar de lo humano en la educación". En primera instancia, un elemento que ha salido a flote y que es fundamental es la importancia del otro para el aprendizaje. Como afirma Wulf (2008), buena parte de las competencias sociales y culturales se adquieren por imitación: el aprendizaje mimético es clave en cualquier proceso social, sin que por esto lleve a que se pierda el ejercicio de configuración de la individualidad, tan importante en los procesos de configuración del lugar crítico de los sujetos, pues: " los seres humanos no se encuentran desatendidos de sus propio proceso de formación; no están subordinados de forma totalmente dócil a absorber conductas que le son cargadas por el grupo" (Hernández y Arteaga, 2019, p. 279).

A partir de la imitación, de lo que se replica del otro o de los otros, surge la capacidad de identificación. En los niños, estas capacidades miméticas facilitan su participación en los procesos culturales de las sociedades a las que pertenecen, es justo de esta manera en la que se van apropiando de los productos simbólicos de sus contextos socioculturales, lo interiorizan y preservar y posteriormente los transmiten a otros sujetos (Wulf, 2008, pp. 182-183). Generalmente esta imitación se da a través del cuerpo, el cuerpo es el que permite imitar, es el elemento central. La imitación contribuye a modelar el entorno: cuando se imita, se recrea lo que se aprende del otro. Estas recreaciones apuntan fundamentalmente a la transformación del entorno, buena parte de las dinámicas sociales y culturales que se han venido aprendiendo se dan por procesos de imitación. Este aprendizaje mimético no se restringe exclusivamente al espacio escolar, se aprende en todos los contextos de lo humano.

En segunda instancia, se hace referencia, teniendo en cuenta su urgencia a partir de una fuerza mayor como esta pandemia, a que no puede haber 
humanidad si no hay igualdad. En el grado de inequidad en el que el ser humano se encuentra, varias novedades surgen, por ejemplo, ¿̇por qué preocupan más unas vidas que otras?, ¿̇por qué se piensa que algunas vidas pueden dejarse a un lado y otras no?, ¿qué está llevando a eso? Aquí es de suma importancia pensar en la necesidad de romper los esquemas conceptuales sobre lo humano: ¿qué es realmente lo humano?, ¿por qué estás dinámicas llevan a considerar que unos sujetos pueden ser más valiosos que otros? Es importante retomar lo planteado por Judith Butler (2010) cuando sostiene que estas formas que han conseguido naturalizarse, en la que se asume que algunas vidas humanas tienen mayor valía que otras, están mediadas por situaciones de orden político y económico. La filósofa norteamericana encuentra que es justamente en las guerras, o en otros momentos de enormes tensiones como el que atravesamos, cuando este tipo de miradas suelen implantarse, de esa forma las vidas de los sujetos del lugar contrario, "los otros", pierden cualquier rastro de humanidad y por eso no debería doler su deceso, en ese caso, se conciben como vidas dañadas o vidas perdidas, pues no consiguen, dentro de los procesos de normativización, ser reconocidas como dignas de ser vividas.

Se hace necesario empezar a trabajar fuertemente en la escuela para lograr romper estos esquemas conceptuales, que muchas veces están ideados desde posturas políticas con intenciones meramente económicas y que encuentran eco en las constantes expresiones de racismo, xenofobia y aporofobia, concepto, este último, que recientemente viene desarrollando en la filósofa española Adela Cortina, para referirse al rechazo a las personas pobres.

En tercera instancia, si a algo el ser humano se ha enfrentado en este proceso de cuarentena y confinamiento, es justamente a pensar una educación que vaya más allá del desarrollo de contenidos y temáticas aislados, es clave que la escuela ahora más que nunca propenda por 
enfrentar estos problemas, la sociedad tiene que aprender, y con ello cada sujeto, a acercarse a los problemas, a entenderlos y, fundamentalmente, a enfrentarlos. Por eso, es necesario reconocer que la escuela no está desvinculada de lo que ocurre socialmente, por el contrario, como afirman Arteaga y Hernández,

En el mundo educativo las interacciones con las realidades contextuales, además de la percepción, asimilación, concepción y evaluación de los contenidos disciplinares y el desarrollo cognoscitivo, no son procesos disociados. Por el contrario, todos movilizan la estancia dentro de la escuela y condicionan a un ser que se va amalgamando a los otros en situaciones pedagógicas que favorecen una construcción de lo que se entiende como el "sí mismo". (2018, p. 59)

Por eso, efectivamente se debe pensar en una escuela que problematice y que brinde más elementos de orden crítico, de capacidad de discernimiento. Las temáticas son relevantes y los contenidos son importantes, pero el gran problema que se ha dejado ver con mayor ahínco es que la sociedad se está

quedando allí, en el desarrollo de contenidos y temáticas aisladas, y poco se apuesta por generar posturas críticas en los estudiantes.

\section{Educación en tiempos de pandemia: un asunto para seguir repensando}

En este tiempo se hace necesario poder analizar y repensar lo que está sucediendo en la contemporaneidad, siendo un momento histórico para Colombia y para el mundo entero, por eso se introduce la reflexión desde unas preguntas iniciales: ¿de qué escuela se habla hoy? ¿Qué condiciones están dadas para que se dé la educación?, una educación que se direcciona, para el caso colombiano, desde el Ministerio de Educación Nacional (MEN), donde su centralidad hoy está dispuesta en la virtualidad. 
Es, a partir de estas preguntas preliminares, que se presentan algunas ideas de la situación problémica que permiten repensar las realidades y analizar el contexto concreto de los estudiantes: las vivencias y dificultades a las que se tiene que enfrentar un maestro. Para el caso de este apartado del texto, en el departamento del Cauca, el cual tiene complejas necesidades y problemáticas de orden estructural históricamente construidas. Por eso, desarrollando unas primeras premisas, parece importante mostrar cómo esta situación expone con fuerza la dificultad estructural que se vive a nivel social, político y económico; además de los campos de la educación y de la salud; solo para mencionar algunos aspectos. En cuanto a la salud, las condiciones en las que están trabajando son mínimas, no cuentan con material suficiente ni equipamiento para el desarrollo de su labor; el hacinamiento en las clínicas, el malestar de la comunidad y la baja atención al público, entre otras situaciones, reavivan con mayor profundidad las formas de privatización del sector y lo dejan en condiciones difíciles de manejar.

Pero la educación no se aparta de esta crisis y de estas problemáticas de orden estructural, que hacen su tránsito por todo el país y el mundo entero. Hoy se encuentra una escuela que tiene históricamente conflictos de diverso orden, o como lo expresan Euscátegui y Pino (2010), "las estructuras curriculares de las instituciones educativas se han caracterizado por estar cargadas de un marcado enciclopedismo, faltos de coherencia y claridad frente a los procesos educativos y [a] su poca relación con el contexto" (p. 25), asunto que lleva a direccionar el currículo de forma descontextualizada, unidisciplinar y fragmentada, regido hoy por “competencias y estándares". Todo esto aunado a la expresión viva de la deserción, producto de diversas fuerzas que cohabitan la región, entre las que sobresale el conflicto armado interno que violenta a las comunidades y las despoja de sus territorios, de sus vidas; además, de lo otro que ocurre 
cotidianamente en la escuela, como lo expresa Márquez (2002): “En Colombia los problemas reflejan altas tasas de repitencia, deserción, deficiencia docente y pedagógica, inadecuados materiales e infraestructura, un $13 \%$ de analfabetismo [asociado] a los graves problemas sociales que afectan directamente a los niños y jóvenes" (p. 30), aspectos que traen toda una historia de inequidades y desigualdad y que dejan a la educación subsumida en el abandono estatal y con poco reconocimiento social. Es por ello imperioso acentuar la reflexión en las prácticas anquilosadas y tradicionales que persisten en la educación y que han constituido la escuela de la repetición, de la memoria o, como afirma Albán (2013), de la tradición, en este sentido, el autor nos dice lo siguiente: "El conocimiento así ofrecido no podía más que volvernos reproductores memorísticos de hechos, acontecimientos, [...] inscritos en una realidad que tenía más de 'extraño' a nuestro entorno más cercano, que familiar. Lo sabido no era otra cosa que lo impuesto" (p. 34).

Estos aspectos, adquieren un sentido mayor en una región cargada de violencias que transita el territorio y que complejiza aún más la tarea educativa, porque, como indican Añanos y Bedmar (2006), no se puede "ignorar que la escuela es un microcosmos en el que se dan los mismos conflictos que en el exterior, sería actuar con miopía pedagógica. El conflicto y la violencia no pueden ser contenidos ajenos a la educación escolar" (p. 25). La escuela y la educación, entonces, están inmersas en sus propios problemas y en los de la sociedad, lo que le significaría pensarse y hacerse distinto y tener en cuenta los contextos, los territorios y las culturas, porque los sujetos no entran al aula desprovistos de sus arraigos, tradiciones, saberes y problemáticas.

En medio de estas condiciones, llega un virus que exige cambios en las cotidianidades de la sociedad, para, así, enclaustrarla y exigirles a la escuela y a los maestros participar en un trabajo para el cual no estaban preparados. 
Respondiendo a las nuevas dinámicas, se determina por parte del MEN el trabajo en casa a partir de la educación virtual, desconociendo las realidades profundas que viven las comunidades y el mismo maestro, quienes se ven obligados a entrar a la virtualidad en condiciones de desigualdad y de inequidad ante la ausencia de conectividad en diferentes contextos. Incluso, antes de pensar en una equidad en los recursos que posibilitan la virtualidad, cabe decir que hay regiones que carecen de condiciones mínimas como agua potable, energía o servicios sanitarios, reflejando así situaciones de máxima pobreza y, con ello, de desigualdades sociales, por lo que vale la pena preguntarse si se piensa desde el MEN en las realidades contextuales de acceso a la virtualidad o acceso a condiciones básicas, en las ruralidades y en las zonas urbanas, para una educación que se denomina de “calidad”. ¿Dónde está la calidad mencionada en los lineamientos, en los estándares y en los derechos básicos de aprendizaje? ¿De qué escuela estamos hablando? ¿De qué educación? ¿De cuál comunicación? ¿De cuál virtualidad? ¿Para qué? ¿Por qué? Lo que está sucediendo es una muestra del capitalismo salvaje que atropella al ser humano, que sigue imponiendo sus lógicas y que sigue instaurando un sistema colonial con toda su estructura basada en la corrupción, en el individualismo y en el mercado, así las políticas que van surgiendo desde los gobiernos muestran el posicionamiento mercantilista y globalizado, de allí que sea importante poder analizar y ver esas otras perspectivas y reflexiones que permiten actuar distinto, máxime cuando se habla de educación.

Vale la pena indicar que a los maestros les ha correspondido asumir esta tarea del trabajo educativo virtual (en muchos casos con gran desconocimiento), lo que genera temores y expectativas por tratar de cumplir con los estándares establecidos, asunto que lleva a centrar la atención nuevamente en lo instrumental, en la técnica, no en lo pedagógico, y que genera una pandemia mayor: continuar por el camino de la 
despedagogización de la educación y atentar contra la persona; los maestros se enfrentan a las largas horas de trabajo laboral y de preparación de clases, centrados en la educación tradicional de la repetición, además de lidiar con el estrés y la ansiedad, que corroen el pensamiento, el actuar y el mismo ser. Tal como afirma Meirieu (2020):

Temo que las herramientas digitales que dominan hoy en día se basan en su mayor parte en una lógica individual y técnica y que estamos luchando, sin la formación adecuada, para utilizarlas para construir verdaderos colectivos. Además, temo que los intereses financieros en juego sean tan fuertes que nos conduzcan, a pesar de nosotros mismos, hacia una concepción comercial de la educación en la que nuestros estudiantes, cada uno frente a su propia pantalla y en mutua indiferencia, consumen software en lugar de compartir conocimientos. Por eso espero que, en el «después de la escuela», ya no aceptemos la reducción tecnocrática del aula a ejercicios programados y asistencia individual prescritos mediante protocolos estandarizados. Por eso me gustaría que estuviéramos más atentos que nunca a las prescripciones «científicas» que, aunque vestidas con las últimas ropas digitales y neurocientíficas, reproducen sin embargo el viejo modelo conductista de la enseñanza individual programada y consideran al profesor, en el mejor de los casos, como un intérprete, y en el peor, como un obstáculo que el 'todo-digital' podría quizás algún día hacer posible eliminar. (p. 3)

No obstante, las tareas del maestro y de las comunidades estarán enfocadas en resistir a estas formas de educación que absorben y no dan tiempo para pensar, para construir participativa y críticamente otras posibilidades de ser y actuar en comunidad y para hacer entender a la sociedad el valioso papel de la educación y cómo ésta puede contribuir a transformaciones en sus estructuras, en un ejercicio de reexistencia, de persistencia y de lucha, que permitirá movilizar y construir otros caminos educativos y pedagógicos pensados desde las realidades, desde los propios contextos. 
De ello, resulta necesario decir que hay un gran reto para los educadores: tratar de construir la otra educación, la otra escuela, la que se piensa distinto y se construye desde la participación y el diálogo de saberes. Por eso, el pensamiento de Paulo Freire en la Pedagogía de la indignación (2010) recuerda que la academia tiene un papel muy importante, seguir pensando las problemáticas y atemperar las reflexiones y acciones a estas realidades, como, también, seguir denunciando lo que está pasando y anunciando los nuevos retos que hoy llegan. Es así como la tarea del maestro es seguir trabajando por otras formas de poder, de comunicación, de relación y de organización y repensar la escuela y el papel mismo de los educadores, de tal manera que se logren construir nuevas propuestas pedagógicas a partir de un ejercicio que permita movilizar el pensamiento y las prácticas desde otros escenarios, para retomar la esencia de lo educativo y pedagógico, la comunicación entre las personas, los encuentros, las conversaciones, los diálogos y los sentires. Es a partir de estos significados que las búsquedas y las luchas tendrán que seguir reconfigurándose y recreándose, para, así, continuar un camino que hoy pareciera incierto, pero que se empieza a vislumbrar desde las comunidades indígenas, las comunidades afrodescendientes y las comunidades campesinas, donde se empiezan a dar visos para mostrar que existen otros caminos, así que vale la pena seguir en el encuentro, movilizarse y construir con la esperanza de que otro mundo es posible.

\section{Educación en tiempos de pandemia: ¿de qué escuela debemos empezar a hablar?}

La sociedad se encuentra en un apartado de la historia que sugiere, así como ya Gabriel García Márquez lo habría relatado en varias de sus obras, mayor sentido y consciencia sobre la condición humana, no sobre lo que aparentemente esta es, sino sobre lo que se está siendo desde ella y desde todos aquellos vínculos que hacen que el ser humano sea en este y en otros 
planos del pensamiento: pensarse como humanidad. Hoy, como lo hizo José Arcadio Buendía lo hizo en su momento, es necesario reunirse, escuchar y actuar, ahora más que nunca existe un compromiso claro como humanidad (García Márquez9, 1967).

Lo anterior convoca a reflexionar en torno a dos temas que en esencia podría parecer obvios, no obstante, en estos tiempos de pandemia no lo son como se creía. El primero de ellos tiene que ver con la idea de escuela y como esta se ha imaginado, diseñado, configurado y edificado por cada uno de los actores del sistema educativo, en estos tiempos de incertidumbre; el segundo, no menos importante, se refiere a lo que se ha llamado el tiempo fuera de la escuela convencional, donde esta pandemia ha llevado a reflexionar sobre el papel de la escuela en la sociedad y viceversa. Ante las insinuaciones y provocaciones que estas dos posibilidades temáticas traen consigo, se atenderán en tres breves momentos: el primero, referido a una aproximación a la idea de la escuela desde diversas perspectivas y sentidos en clave de este momento histórico que acontece; el segundo, una breve conclusión que en sí no pretende ser una conclusión como tal, sino un intento de conclusión que buscaría estimular otras reflexiones posibles ante los temas citados; el tercero, los retos que supone el momento actual frente a lo que es la escuela y su tránsito a una idea polisemántica y con más notable profundidad.

Pues bien, en esta medida, se ha comprobado que la escuela es un asunto de perspectiva y de vinculo, es decir, depende del sujeto, el cual puede tomar el rol de espectador o de actor. De allí, de esa elección, se supondrá el resto. Aparentemente, desde la introspección que convoca reflexionar sobre este asunto, el Estado ha pensado en una escuela donde lo más importante sea continuar sin alterar el ciclo de la vida misma, pensando en los estudiantes y maestros como difusores o propagadores del virus, que deben reportarse con mil y una tareas sin ningún fin más que el de mantener ocupados a 
ambos. En este escenario es más importante el progreso en términos desarrollo de los periodos o semestres, que el progreso en términos de humanidad. Por su parte, las instituciones educativas buscan seguir, sobre la marcha, intentando, pretendiendo y queriendo construir desde otras perspectivas, motivados más desde la voluntad de aquellos comprometidos con la formación, que otra cosa (Montenegro, 2017). Ahora bien, les han impuesto a las instituciones educativas o ratificado en algunos casos, la tarea de ser, en términos de Foucault (2003), un gran panóptico, impidiendo pensar la escuela más que como lugar, trabajo o rutina.

Por otro lado, los padres de familia han hecho una vida lejos de sus hijos, pensando la escuela como un parqueadero donde les ayudan a ocuparse de ellos, como si su tiempo, sueños, ilusiones y aconteceres irremediablemente estuviesen en un segundo plano. Estos son los resultados de esta dinámica de producción y reproducción de las insoportables rutinas que recuerdan que el ser humano no es dueño o amo de nada, donde lo importante es que los niños, jóvenes y adultos estén ocupados, haciendo algo, lo que sea. Además, se pretende solucionarlo desde ciertas muletillas como, por ejemplo, ¿cómo te fue en la escuela?, ¿qué aprendiste?, ¿̇e comiste todo?, ¿qué te dijo el profesor?, en vez de hacer preguntas de mayor implicancia. Ahora que están en la casa, en familia, ¿qué se va a preguntar?, ¿̇en qué se van a ocupar?, ¿con que se van a distraer? ¿de qué manera pueden los niños y jóvenes dejar trabajar al adulto? Quizás sea una oportunidad valiosa la de hacer escuela en casa, la de aprender y enseñar a vivir, la de pensar y reflexionar y, sobre todo, la de tener valor y coraje para asumir la formación como un gran proyecto a varias manos; al parecer, si de algo se ha reflexionado en esta pandemia, es de que la tarea de la escuela no es fácil, es apoteósica (Montenegro, 2015; Montenegro, 2017).

Por otra parte, los maestros están queriendo innovar la escuela, sin embargo, esta innovación ha estado motivada más desde la necesidad o la 
urgencia, que este escenario de coyuntura ha provocado, que desde un escenario idóneo para la reflexión. En este momento, se requiere de toda la creatividad, paciencia, honestidad, autorregulación, conocimiento, profesionalismo y, de manera sustantiva, de mucha humanidad. Ahora los roles en la escuela se debaten entre ser youtubers, influencers, creadores de contenido y videobloggers, entre otras denominaciones propias del mundo virtualizado. Sin embargo, la categoría de maestros tomará un nuevo sentido desde la idea disruptiva de una escuela vista desde el afuera y la cotidianidad y dirigida hacia lo esencial, lo elemental y lo importante. Hoy el maestro se aleja del vínculo con el estudiante a través de la presencialidad y deja a la escuela física para acercarse a nuevas formas de encontrarse, tal vez, sean estos nuevos escenarios mecanismos para entender los apoteósicos cambios de la globalidad y la hiperconectividad.

Finalmente, a los estudiantes, a los maestros y a la escuela en sí misma, hoy, les ha tocado hacer frente a esta complejidad y pensar la formación, la enseñanza y el aprendizaje de otras formas, tal vez, de maneras nunca imaginadas, que, incluso, llevan a reflexionar sobre el propósito de la vida misma; muchos, filosofando desde sus ventanas sobre cómo se está difuminando el tiempo terrenal; otros, desde sus lugares, pensando cómo "salvar" este año escolar.

Ahora se ha vuelto común el estribillo "que felices éramos y no lo sabíamos", la felicidad es de las cosas más irónicas que puedan existir, nunca se puede llegar a saber, puede que lo mejor esté sucediendo en este momento. Se ansiaba salir de las escuelas o lugares de trabajo, y resultó que la escuela y el trabajo en casa son más complejos y temerarios.

En conclusión, no hay virus más mortal que la indolencia e inhumanidad de la gente; esta pandemia es quizás una de las pruebas más complicadas que la sociedad entera ha afrontado en los últimos tiempos, ha tocado a todos los seres humanos; no hay puntos extras, notas apreciativas, trucos, trampas 
o suerte que, aparentemente, permitan evadirle. Muchos no estaban preparados, no se ha estudiado y practicado la lección más importante: el sentido humano de cada persona.

En estos tiempos de pandemia, no solo son necesarios la conectividad y los equipos que sirven para virtualizar y virtualizarnos, quizás, lo que más se requiere es el reconocimiento de la condición humana, del otro, de lo otro, de la hermandad, no solo entre los sujetos sino con todos los elementos vivos de este maravilloso universo (Montenegro, 2014). Al parecer, nunca se estuvo tanto en la escuela como ahora, que se ha reconcebido como el viaje interno y la travesía histórica, lo que es y será la mayor escuela.

Así pues, el reto será repensarse y perfilar otra idea de escuela, pactar consigo mismo el cambio de paradigma. En esta misma línea, la incertidumbre y la trasformación son dos variables muy intensas que habitan el acontecimiento-mundo. Hoy, hay un momento para atender con mayor atención cuestiones como la violencia, la inequidad, la subalternidad, la contaminación, los derechos humanos y, claro está, no podría faltar, la formación, más allá del sentido de lo instruccional y escolar (De Sousa Santos, 2020). En últimas, Lennon tenía razón cuando decía que "la vida es aquello que te va sucediendo mientras estás ocupado haciendo otros planes".

\section{Consideraciones}

Con el ánimo de no cerrar, sino dar apertura a otros diálogos, es necesario seguir preguntándose por la postura de la escuela y tener en cuenta que cuando se habla de escuela se hace en sentido genérico. Así mismo, es importante intentar responder las siguientes dos preguntas: ¿̇cuál es el lugar de la escuela en estos tiempos de contingencia? y ¿cómo desde el campo educativo se preserva lo humano?, justamente, porque, en las condiciones en las que está la sociedad, la educación es un actor principal en tanto 
provee espacios para el encuentro con el otro y los otros. Así como lo educativo posibilita reflexiones y comprensiones de mundo, también puede contribuir a la defensa de lo humano en estos contextos que siguen respondiendo a hegemonías occidentales y al mundo capitalista, lo cual se refleja en estos espacios de fisura pandémica.

Segundo, se hace urgente mirar la función de la educación, ¿̇es esta una educación que acompaña la humanidad? O, por el contrario, ¿̇es una educación que compite en desigualdad?, porque el sentido de lo educativo se ve alterado cuando se denotan actos que aniquilan al otro, a ese otro diferente y diverso. Al parecer, la educación, y con ella la escuela, se ha quedado anquilosada en los viejos paradigmas tradicionales, que, si bien han sido importantes en el campo educativo, han dado la espalda a las transformaciones y a los nuevos sujetos que hoy transitan la escuela. Además, ¿qué decir de lo que se enseña? Esta pregunta es importante, pensando en una enseñanza que solo cambia de pizarras y que desconoce al otro en su humanidad: al contexto, a las culturas, a los sentires y a las historias de los pueblos y las comunidades.

Y, tercero, la invitación con estas reflexiones a lo largo del texto es mirar las prácticas y discursos y pensar cómo, desde el lugar en el que cada ser humano se encuentre, se pueden establecer espacios de comprensión de las contingencias por las que pasa la sociedad. ¿Cómo, desde el rol del docente y del estudiante, movilizar fuerzas de humanidad?; ¿cómo leer críticamente las realidades en las que cada uno se encuentra?; ¿cómo centrar la mirada en las cotidianidades, en lo urgente, en lo importante, para lograr construir desde el entorno, en este caso el educativo, momentos de humanidad que posibiliten el encuentro de todos? 


\section{Referencias}

Albán, A. (2013). Más allá de la razón hay un mundo de colores: modernidades, colonialidades y reexistencia. Editorial Oriente.

Álvaro, D. (2010). Los conceptos de comunidad y sociedad de Ferdinand Tönnies. Revista CEIC, 1(52), 1-24. https://identidadcolectiva.es/pdf/52.pdf

Añanos, F. y Bedmar, M. (2006). Educación social: formación, realidad y retos. Grupo Editorial Universitario.

Arteaga Quintero, M. y Hernández, C. (2018). Ficción y autoimagen. Una aproximación al "sí mismo" a partir de la lectura de textos narrativos. Revista Paradigma, XXXIX(1), 58-77. http://revistas.upel.edu.ve/index.php/paradigma/article/view/6776/3873

Butler, J. (2010). Marcos de guerra. Las vidas lloradas. Ediciones Paidós.

De Sousa Santos, B. (2020). La cruel pedagogía del virus. Consejo Latinoamericano de Ciencias Sociales (Clacso). http://209.177.156.169/libreria cm/archivos/La-cruelpedagogia-del-virus.pdf

Euscátegui, R. y Pino, S. (2010). Los procesos educativos y curriculares resignificados desde la formación humana. Editorial Universidad del Cauca.

Foucault, M. (2003). Vigilar y castigar. Siglo XXI Editores.

Freire, P. (2010). Pedagogía de la indignación. Ediciones Morata.

García Márquez, G. (1967). Cien años de soledad. Editorial Sudamericana.

Hernández, C. y Arteaga, M. (2019). Diálogos transdisciplinares: antropología históricopedagógica y teoría de la recepción. Revista Arjé, 13(25), 276-293.

Meirieu, P. (2020, 18 de abril). “La escuela después”... ¿̇con la pedagogía antes? Movimiento Cooperativo de Escuela Popular (MCEP). http://www.mcep.es/2020/04/18/la-escuela-despues-con-la-pedagogia-de-antesphilippe-meirieu/

Montenegro, L. (2014). Del cómo la ciudad es una configuración cultural. Boletín Informativo CEI, 1(1). http://editorial.umariana.edu.co/revistas/index.php/BoletinInformativoCEI/article Lview/397 
Montenegro, L. (2015). Aproximaciones iniciales a la bildungsroman. En Universidad Mariana (comp.), Reflexionando la educación. Memorias de los encuentros nacionales e internacionales en pedagogía investigación y cultura (pp. 233-241). Editorial Universidad Mariana (Unimar). http://editorial.umariana.edu.co/libros/index.php/editorialunimar/catalog/book/8 4

Montenegro, L. (2017). Experiencia y formación. Boletín Informativo CEI, 3(3). http://editorial.umariana.edu.co/revistas/index.php/BoletinInformativoCEI/article $\not$ view/1157

Wulf, C. (2008). Antropología. Historia, cultura, filosofía. Anthropos Editorial. 